\title{
Analysis of the impact of damage to the injection system on the emission of toxic substances in a spark-ignition internal combustion engine
}

\begin{abstract}
The article presented analyses the impact of damage to the injection system on the emission of toxic subsumes in a spark-ignition internal combustion engine. The work focuses on the basic elements of the injection system, which include injectors, throttle position sensor, coolant temperature sensor and lambda sensor. In addition, a catalytic reactor has been included in the context of its direct cooperation with the injection system under set conditions. The toxicity of exhaust gases of different spark-ignition engines fueled with petrol or gas in determined operating conditions using the MAHA MGT5 exhaust gas analyser was tested. The content of toxic substances in the exhaust gases was recorded for the correct settings of the injection system and for the engine working with damage to this system. The tests carried out will allow to assess the impact of the damage of the injection system on the toxicity of exhaust gases.
\end{abstract}

Key words: spark-ignition internal combustion engine, exhaust gas toxicity, exhaust gas standards, injection system damage, exhaust gas analyzer

\section{Introduction}

An essential aspect of the emission standards is the proper condition of the internal combustion engine. Even the smallest damage to the fuel supply system can result in the fact that an engine approved for use and meeting the standards valid at the time it was produced will significantly exceed the emission thresholds. Consequently, damage to the injection system cannot be ignored by the car user. Any error message, or a visible symptom, i.e. power drop or uneven engine operation must be checked immediately for correctness and emissivity.

The content of toxic components in the exhaust depends not only on the engine's operating conditions, e.g. its thermal status, rotational speed, load. An important role is proper condition of the engine (e.g. the ignition advance angle, the correct operation of the exhaust gas recirculation system), and in particular the correctness of the mixture composition regulation. In MPI engines, dominating among spark-ignition engines operating on a mixture with a stoichiometric mixture, any change in the composition of the mixture results in a change in the amount of individual toxic components.

Another factor that affects the content of toxic components in exhaust gases is the technical condition of the exhaust gas treatment system - oxidation and reducing catalysts. Properly working exhaust after-treatment system a three-way catalyst reduces the content of harmful $\mathrm{HC}, \mathrm{CO}$ and NOx combustion products in the exhaust. The composition of the exhaust depends not only on the quality of the combustion process taking place in the engine, but also on the technical condition of the components of the exhaust after-treatment system. For these reasons, the measurements of the toxicity composition of exhaust gases do not control whether the engine is ecological, but they are an important indicator of its technical condition $[9,10]$.

The measurements of the exhaust composition allow first of all for the general assessment of the correctness of the combustion process in the engine, determination of the technical condition of the ignition and fuel system, the system of regulating the composition of the mixture and devices limiting the emission of harmful exhaust components. On the other hand, they do not allow to obtain a clear indication of the cause of the increase of toxic components emission. Therefore, diagnostic inference is based primarily on the analysis of the concentrations obtained for individual components and the knowledge and experience of the person performing the measurement.

If the combustion process in the engine is appropriate, the oxygen content in the exhaust gas should be within the range of $0.05-1 \%$, the $\lambda$ coefficient should be as close as possible to 1 , the carbon dioxide content should be $14.5-$ $16 \%$, while the $\mathrm{CO}$ and $\mathrm{HC}$ (higher at idle speed than when the engine is running at high speed) should be smaller than the control values. For modern engines, the hydrocarbon content should not exceed $30 \mathrm{ppm}$. Measurement results differing from the above indicate a change in the ability of the engine.

For the tight exhaust system, the sum of the percentage of $\mathrm{CO}_{2}$ and $\mathrm{CO}$ in the exhaust gas should be $15-16 \%$. Significantly increased oxygen content in the exhaust gas, accompanied by a reduced concentration of carbon dioxide, indicates leakage of the exhaust system, and an increased content of hydrocarbons means a leak before the lambda sensor placed in front of the catalyst, which causes a malfunction of the lambda sensor and excessive enrichment of the mixture regulation [1].

The increased content of carbon monoxide, the reduced content of carbon dioxide and the high content of hydrocarbons indicate a poor thermal condition of the engine caused by, for example, damage to the coolant temperature sensor. This may indicate an incorrect combustion process. The reason may be improper operation of the mixture composition adjustment, damage to the lambda sensor or injectors, damage to the intake air temperature sensor, damage to the 
air flowmeter or a permanently open valve in the circuit absorbing fuel vapors $[4,5]$.

A low $\mathrm{CO}_{2}$ concentration and a low $\mathrm{CO}$ concentration below $0.1 \%$, as well as a lambda value greater than 1.03 , indicate a lean mixture. If there is a high content of hydrocarbons in the exhaust, this also indicates a leak between the piston and the sleeve. Defects in the ignition system (coils, spark plugs or wires) cause ignition failure - no fuel combustion.

A high hydrocarbon content of more than $30 \mathrm{ppm}$ resulting in low carbon dioxide and high carbon monoxide is the result of catalyst malfunction.

The value of $\lambda$ coefficient higher than 1.03 , with a low content of $\mathrm{CO}$ and $\mathrm{CO}_{2}$ as well as a high content of $\mathrm{HC}$ and $\mathrm{O}_{2}$, indicates that the mixture is too lean. The reason may be the lowering of the actual mass value of the sucked air indicated by the flowmeter due to the suction of additional air and leakages of the intake system behind the flow meter. The value of the coefficient $\lambda$ lower than 0.97 , with a high content of $\mathrm{CO}$ and $\mathrm{HC}$ and low $\mathrm{CO}_{2}$ and $\mathrm{O}_{2}$, most often results from the excessive enrichment of the mixture caused by damage to the lambda sensor.

\section{Analysis of the fuel system in spark-ignition engines}

Fuel at a pressure of 1 bar in single-point SPI fuel injection is injected into the throttle area. The impact on the formation of a homogeneous fuel-air mixture has many factors. The most important is the high air velocity, thanks to which it is possible to mix the fuel with air. The conditioning factor is the air temperature above the throttle assembly. It can be heated not only by the heat emitted from the engine, but also by additional installation of engine coolant lines, or an electric heater.

The multi-point injection system is characterised by the fact that fuel is injected into the area of intake valves into a particular cylinder by means of an individual injector. This system of creating a mixture of fuel and air ensures identical supply of each cylinder. The working pressure on the injection bar is from 3 to 4 bar $[6,7]$.

In modern systems, the ECU (Electronic Control Unit) opens the injector synchronously when the valve is opened to a selected cylinder. The result of this is the creation of a homogeneous fuel-air mixture, which causes a significant reduction in the content of harmful substances in the exhaust.

\section{Analysis of damage to injection system components affecting the toxicity of exhaust gases}

The electric damages of the injector include: shorting the coil and interrupting the continuity of connection with the controller. Mechanical damages include: no fuel flow, no possibility of closing the needle valve due to contamination of the needle seat and lack of patency of the injector filter.

Possible faults associated with the coolant temperature sensor may be a shorting to the ground or open-circuit. The symptoms that accompany the damage may be: increased fuel consumption, increased idle speed or difficulty in starting the engine.
The lambda sensor acts as a feedback in the engine by measuring the amount of oxygen in the exhaust. The amount of oxygen measured is a reference to the air to fuel ratio in a mixture. If the composition of the mixture deviates from the value of $\lambda=1$, the step change of the voltage signal sent by the sensor is immediately recognised and measured by the engine ECU. The signal sent by the lambda sensor varies from about $200 \mathrm{mV}$, meaning a lean mixture up to about $800 \mathrm{mV}$, meaning a rich mixture. The controller, based on the correction factor, changes the injection time, which regulates the proportions of the mixture. In this way, a cyclic change process is created that oscillates around the value of $\lambda=1[2,3]$.

The regulation of the composition of the mixture is carried out on an ongoing basis. This is a requirement for proper operation of the catalytic converter regarding removal of toxic substances from exhaust gases. The correct operation of the catalyst depends on the temperature above $350^{\circ} \mathrm{C}$. Therefore, the composition of the mixture is regulated only after the exhaust system reaches a certain temperature. The correctness of the lambda sensor operation is monitored by the controller, and the faults are shown by MIL [8].

\section{Experimental research}

The aim of the analysis was to test the BMW M10B18 engine with spark ignition (Figure 1) to determine the composition of the emissions of individual exhaust components. The measurements were carried out for proper condition engine and simulated damage. Damage concerned the injection system and the sensors that affect the injection control parameters. Engine tests were performed three times in each damage. The emission of toxic substances was registered with the MAHA MGT5 analyser (Fig. 2).

Emissions tests carried out included:

- Determination of the carbon monoxide content in the exhaust gas of a BMW engine fueled with petrol and in the without ignition in individual cylinders (Fig. 3),

- Determination of the carbon monoxide content in the exhaust gas of a BMW engine fueled with petrol and for simulated damage (Fig. 4),

- Determination of the content of carbon monoxide in the exhaust gas of the BMW engine fueled with LPG and for simulated damage (Fig. 5),

- Determination of the carbon dioxide content in the exhaust gas of a BMW engine fueled with petrol and in the without ignition in individual cylinders (Fig. 6),

- Determination of the carbon dioxide content in the exhaust gas of a BMW engine fueled with petrol for simulated damage (Fig. 7),

- Determination of the content of carbon dioxide in the exhaust gas of a BMW engine fueled with LPG and for simulated damage (Fig. 8),

- Determination of hydrocarbon content in the exhaust gas of a BMW engine fueled with petrol and in the without ignition in individual cylinders (Fig. 9),

- Determination of hydrocarbon content in the exhaust gas of a BMW engine fueled with petrol and for simulated damage (Fig. 10), 
- Determination of the hydrocarbon content in the exhaust gas of a BMW engine fueled with LPG and for simulated damage (Fig. 11),

- Determination of the content of nitrogen oxides in the exhaust gas of a BMW engine fueled with petrol in the without ignition in individual cylinders (Fig. 12),

- Determination of the content of nitrogen oxides in the exhaust gas of a BMW engine fueled with petrol and for simulated damage (Fig. 13),

- Determination of the content of nitrogen oxides in the exhaust gas of the BMW engine fueled with LPG and for simulated damage (Fig. 14),

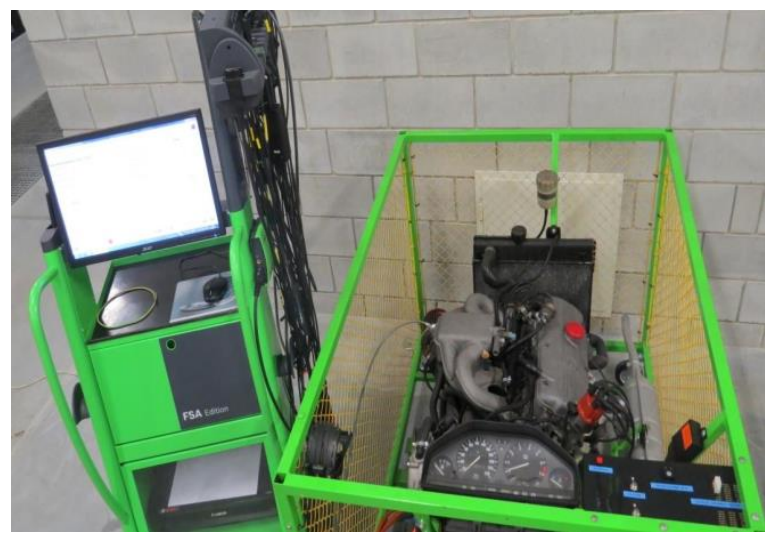

Fig. 1. Test stand with BMW M10B18 engine

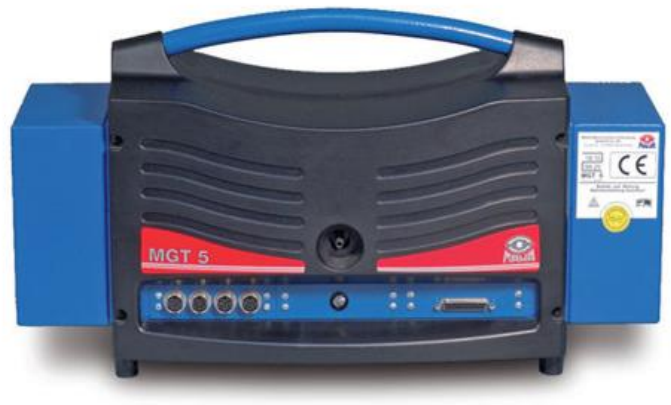

Fig. 2. MAHA MGT 5 exhaust gas analyzer

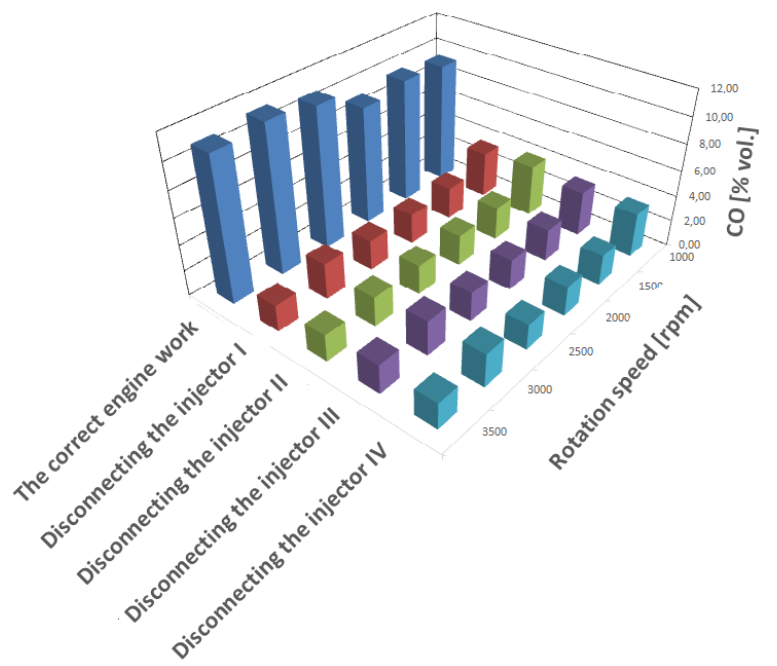

Fig. 3. The content of carbon monoxide in the exhaust gas of a BMW engine fueled with petrol and in the without ignition in individual cylinders

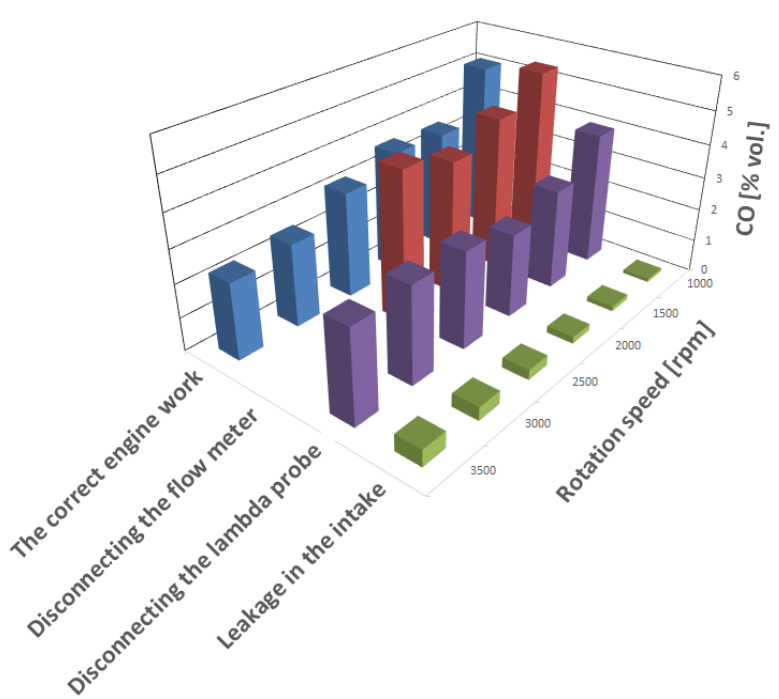

Fig. 4. The content of carbon monoxide in the exhaust gas of a BMW engine fueled with petrol working efficiently and for simulated damage

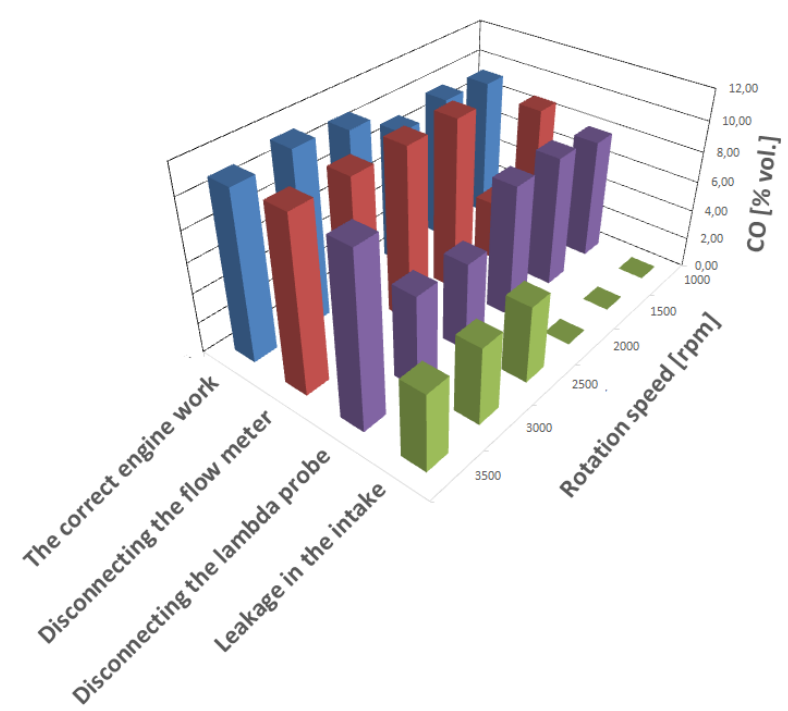

Fig. 5. The content of carbon monoxide in the exhaust gas of a BMW engine fueled with LPG working efficiently and for simulated damage

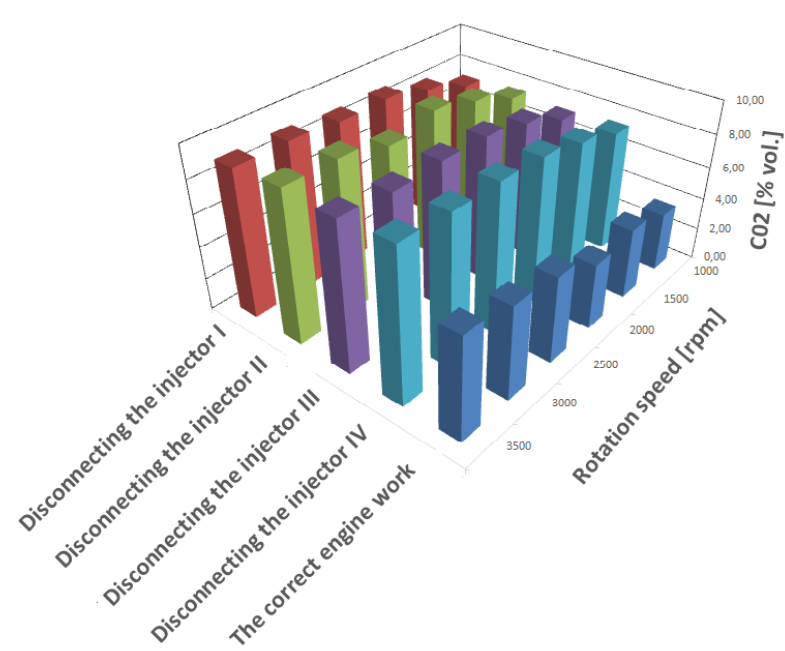

Fig. 6. Carbon dioxide content in the exhaust gas of a BMW engine fueled with petrol and in the without ignition in individual cylinders 


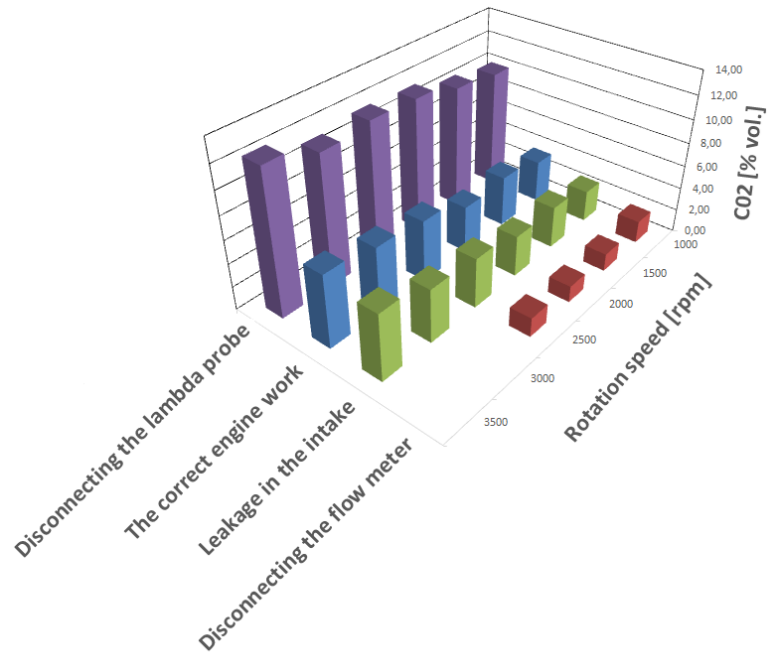

Fig. 7. The carbon dioxide content in the exhaust gas of a BMW engine fueled with petrol working efficiently and for simulated damage

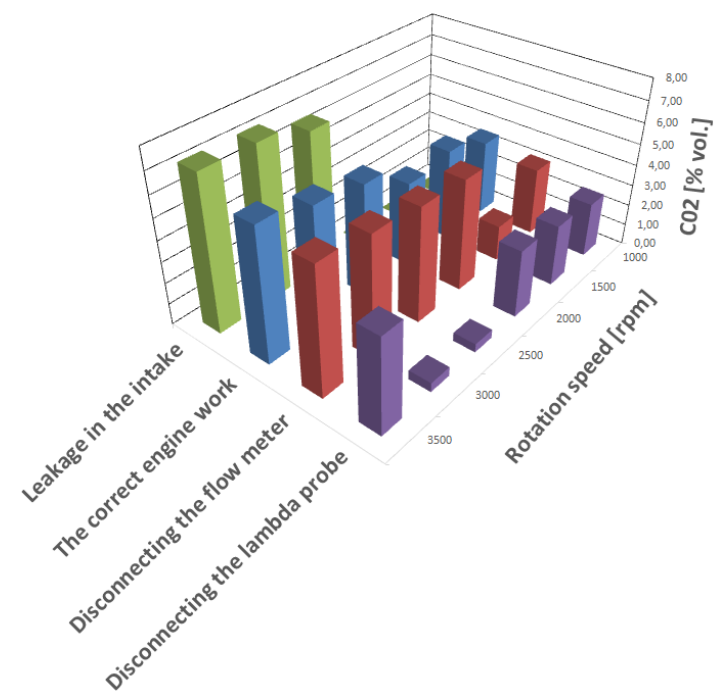

Fig. 8. The carbon dioxide content in the exhaust gas of a BMW engine fueled with LPG working efficiently and for simulated damage

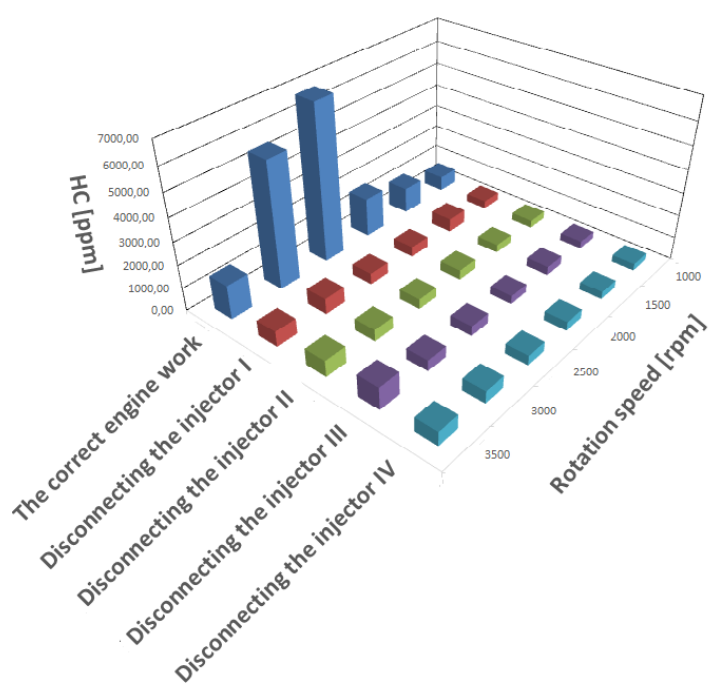

Fig. 9. The hydrocarbon content in the exhaust gas of a BMW engine fueled with petrol working efficiently and in the without ignition in individual cylinders

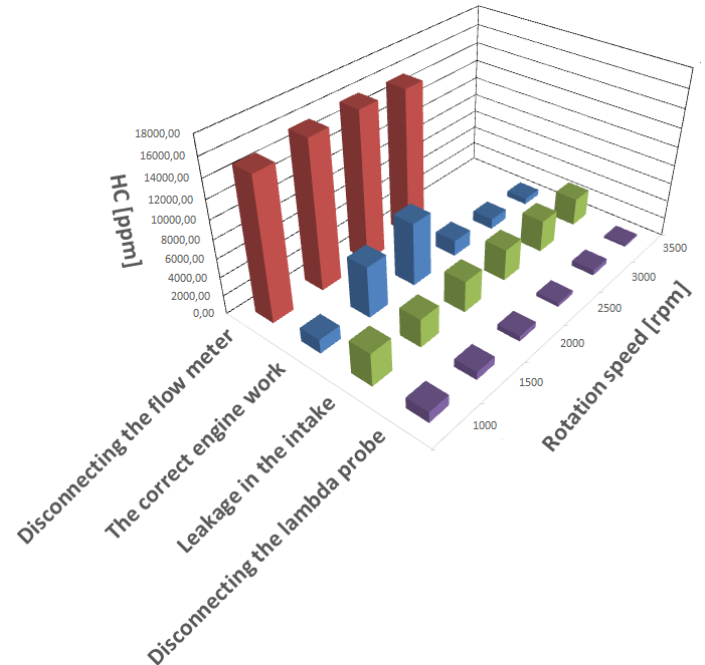

Fig. 10. The content of hydrocarbons in the exhaust gas of a BMW engine fueled with petrol working efficiently and for simulated damage

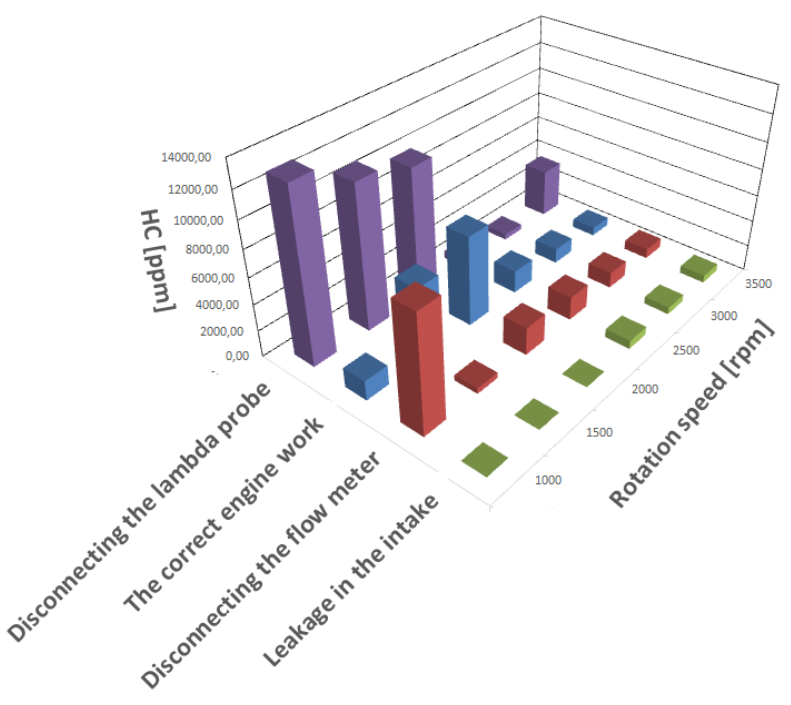

Fig. 11. The content of hydrocarbons in the exhaust gas of a BMW engine fueled with LPG working efficiently and for simulated damage

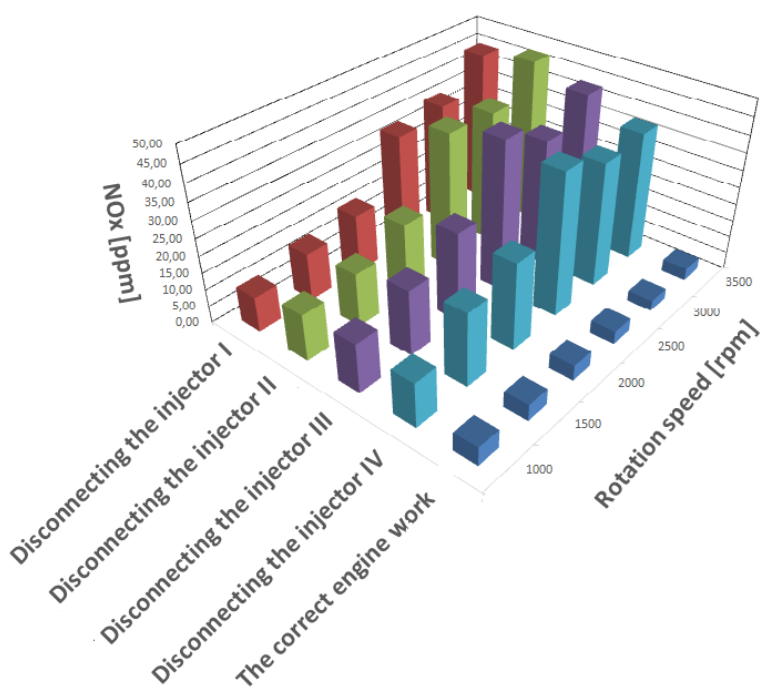

Fig. 12. The content of nitrogen oxides in the exhaust gas of a BMW engine fueled with petrol working efficiently and in the without ignition in individual cylinders 


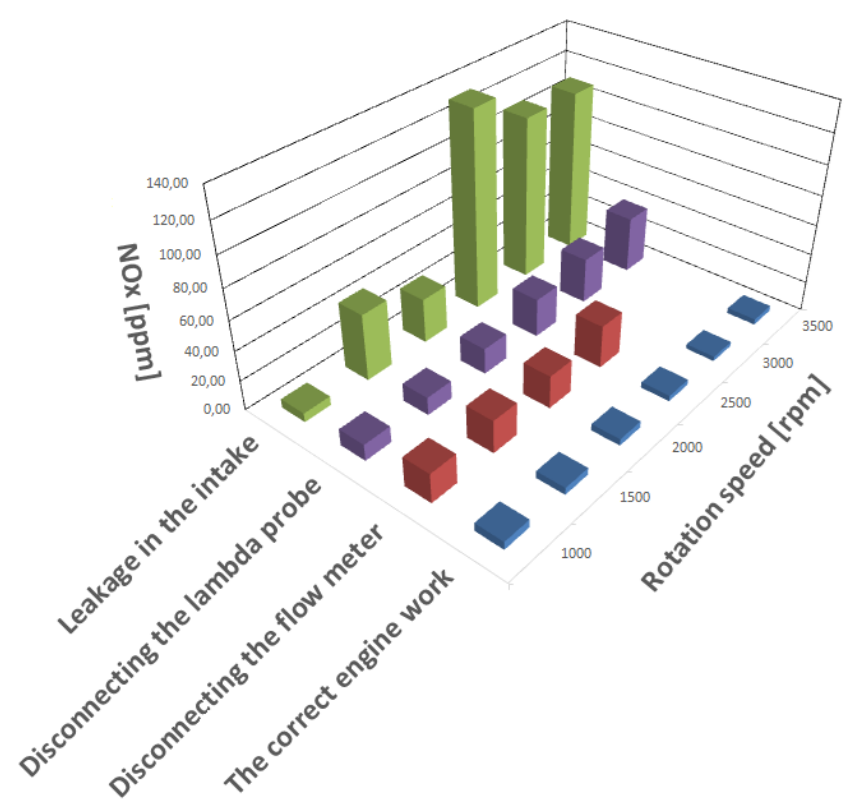

Fig. 13. The content of nitrogen oxides in the exhaust gas of a BMW engine fueled with petrol working efficiently and for simulated damage

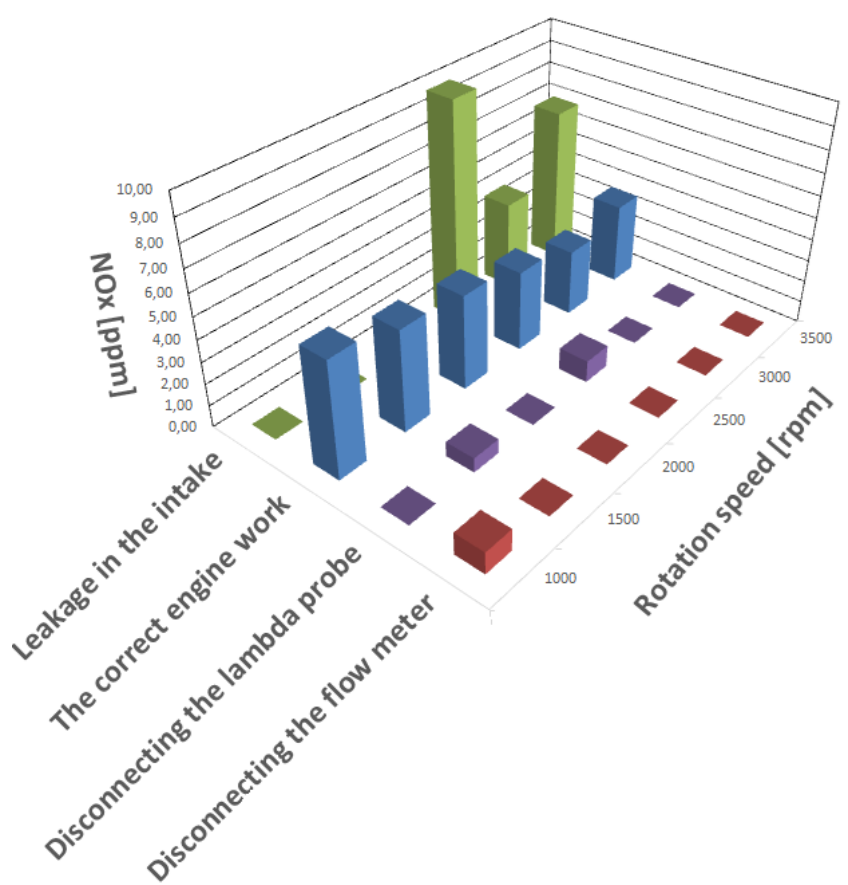

Fig. 14. The content of nitrogen oxides in the exhaust gas of a BMW engine fueled with LPG working efficiently and for simulated damage

Analysing the results of the injection system in the simulation of individual injector faults, the correspondence between the individual cylinders was found. In the case of the emission of nitrogen oxides, a slight increase is visible due to the impoverishment of the mixture to about 1.25-1.3. Concerning hydrocarbon emission, the decrease of their emission is visible at higher rotational speeds when an injector is damaged. An increase in emissions at lower engine speeds may be the result of engine damage. The decrease in the emission of carbon dioxide and carbon monoxide is the result of the without injection on single cylinder. Similar shapes of oxide emission runs and carbon dioxide on individual cylinders show that each cylinder delivers a similar amount of combustion products.

The factors that increase exhaust emission have a damage of injection system. These factors include: incorrect signal from the air flow meter, disconnection of the lambda sensor or a leak in the intake system.

The emission of nitrogen oxides changes significantly in the case of leakage of the intake system. The increase of $\mathrm{NO}_{\mathrm{x}}$ in relation to the correct operation of the engine is visible in the entire speed range.

The change in hydrocarbon emission is related to the leaking of the intake system and increases when the air flowmeter is disconnected. During the tests uneven operation of the engine occurred, causing the hydrocarbons to grow, which caused permanent damage to the measuring system.

The emission of carbon monoxide and carbon dioxide in the simulation of the air flow meter circuit caused the increase of carbon monoxide above the value at the correct engine operation. The carbon dioxide content in the exhaust gases assumes similar values with correct engine operation and disconnected sensor.

Increased concentration of nitrogen oxides in the case of fuelling the engine with LPG occurs when the intake system leaks at a speed above $2300 \mathrm{rpm}$ (revolutions per minute). The reason for this behaviour may be a fuel and air mixture, which is leaked especially for higher rotational speeds. The decrease of nitrogen oxide emission in the case of a disconnection of the lambda sensor and the flowmeter results from the transition of the engine into an emergency mode of operation, which is connected with maintaining the mixture similar to stoichiometric.

Increased hydrocarbon emission values occur only in the speed range from 800 to $2300 \mathrm{rpm}$ with a detachable lambda sensor.

The drop in the concentration of carbon dioxide in the event of the lambda sensor being disconnected and its increase in leakage of the intake system may be caused by a larger amount of sucked air.

Emission of carbon monoxide at rotational speeds from 800 to $2000 \mathrm{rpm}$ is kept constant, after which it rapidly increases due to the impoverishment of the mixture and reaches its maximum value at 2,500 rpm. For higher speeds it maintains a constant value.

Analysing the surface plot of carbon dioxide emission for selected failures (Fig. 15), it can be concluded that the highest $\mathrm{CO}_{2}$ values are obtained at the break in the lambda sensor circuit, and the smallest ones at the break in the flow meter circuit.

The hydrocarbon content (Fig. 16) is the highest at the flow meter circuit, while the smallest HC content occurs at the break in the oxygen sensor circuit.

The carbon dioxide content (Fig. 17) in the exhaust gases of a BMW engine fueled with LPG with an increase in speed for three failures increases as a function of the rotational speed. In the event of a break in the lambda sensor circuit for speeds between 2,500 and 3,500 rpm there is a sharp drop in the content of carbon dioxide.

Emission of hydrocarbons (Fig. 18) as a function of rotational speed reaches maximum values with a break in the 


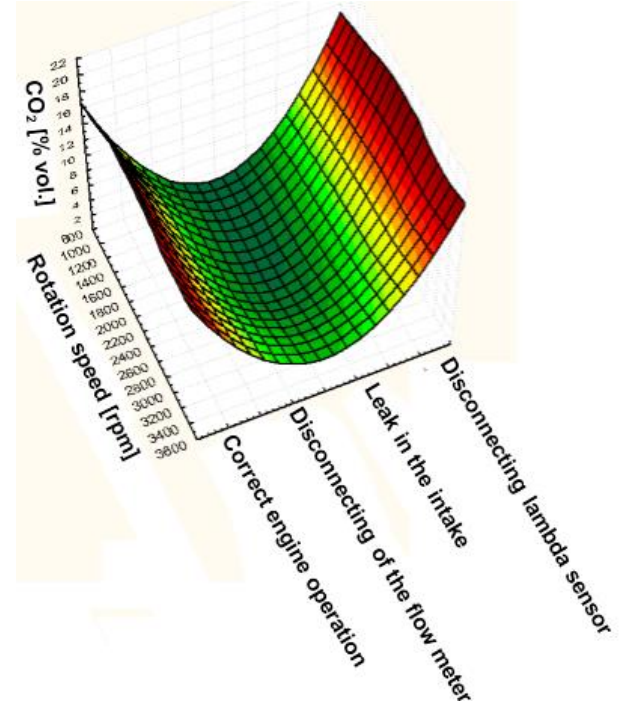

Fig. 15. The content of carbon dioxide as a function of rotational speed for an efficient engine and simulated damage - a petrol-fueled engine

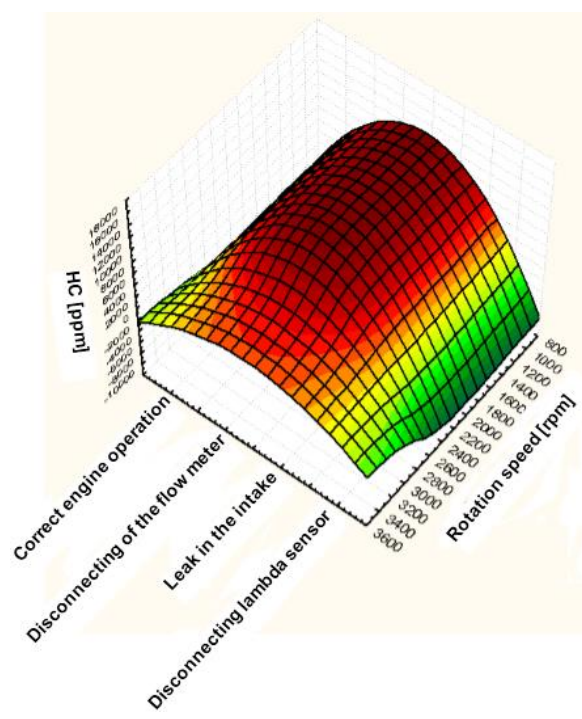

Fig. 16. The hydrocarbon content as a function of rotational speed for an efficient engine and simulated damage - a petrol-fueled engine

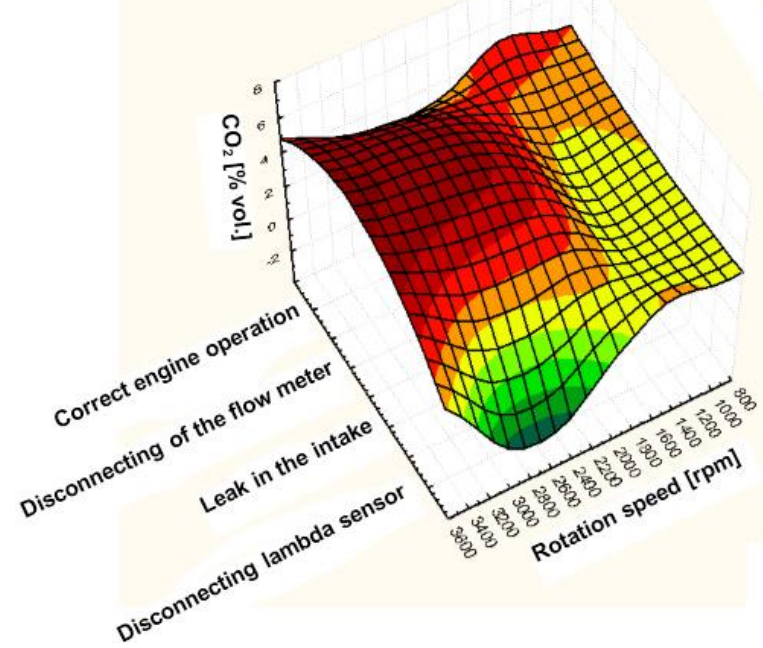

Fig. 17. Carbon dioxide content as a function of rotational speed for an efficient engine and simulated damage - an engine fueled with LPG lambda sensor circuit at speeds from 800 to $1200 \mathrm{rpm}$. The smallest values are achieved when the flowmeter is disconnected and the intake leak is reached.

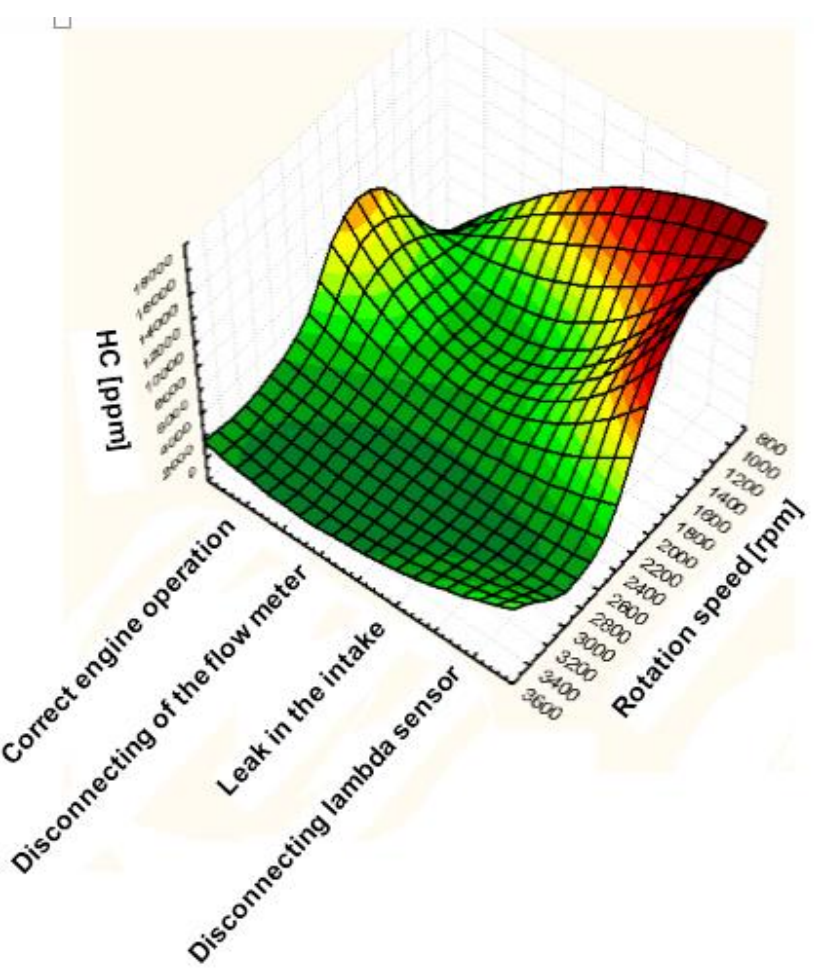

Fig. 18. The hydrocarbon content as a function of rotational speed for an efficient engine and simulated damage - an engine fueled with LPG

\section{Summary}

On the basis of the literature analysis and the tests conducted it can be stated that damage to selected elements of the injection system of a spark-ignition engine affects the combustion process.

Analysis of the measurements made for emission of individual components during fault simulation allows to determine the type of damage to the elements of the injection system. The tests carried out facilitate the diagnosis without interfering with the electrical installation. The use of the exhaust gas analyzer with the measuring apparatus allows to clearly determine the impact of the type of damage on the change of toxic exhaust components. The simulated damage to the flowmeter in the form of a break in the circuit, interruptions in the lambda sensor circuit and leakage in the air path caused the change of engine control, which changed the emission of toxic substances. Comparing the combustion process when switching off individual injectors it can be concluded that the combustion process on individual cylinders was correct taking into account the content of carbon monoxide, carbon dioxide, nitrogen oxides and hydrocarbons as a function of rotational speed, which were similar. The experimental studies carried out constitute input data for the development of algorithms for diagnostic patterns, based on the combination of error codes with the results of toxic components, which will allow to clearly determine the type of damage. 


\section{Bibliography}

[1] CHŁOPEK, Z. Stationary simulation tests of exhaust emission in dynamic tests for Diesel engines with various applications, Combustion Engines. 2011, 145, 35-40.

[2] CHŁOPEK, Z. The methods of synthetic assessment of emissions from combustion engines, Combustion Engines. 2009, 139, 68-76.

[3] DZIUBIŃSKI, M., Badania elektronicznych urządzeń pojazdów samochodowych. Wydawnictwo Naukowe Gabriel Borowski. Lublin 2004.

[4] DZIUBIŃSKI, M. Ecological aspect of electronic ignition and electronic injection system. Environmental engineering V. 2017.

[5] DZIUBIŃSKI, M. Testing of exhaust emissions of vehicles combustion engines, Environmental engineering V. 2017.
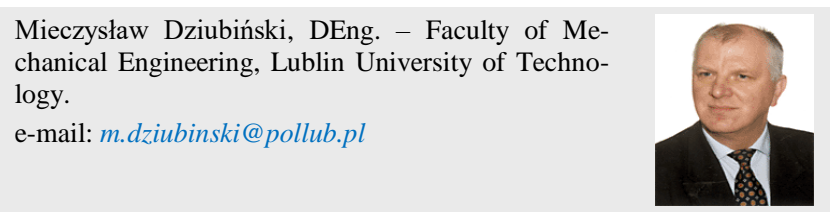

Artur Drozd, MEng. - Faculty of Mechanical Engineering, Lublin University of Technology.

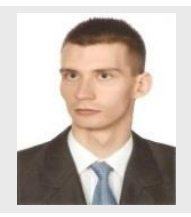

Michał Ścirka, MEng. - Faculty of Mechanical Engineering, Lublin University of Technology.

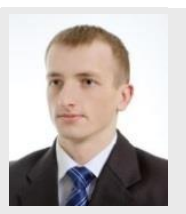

[6] DZIUBIŃSKI, M., WALUSIAK, S. Symulacja pracy układu zapłonowego. Politechnika Lubelska. Lublin 1993.

[7] KĘDZIA, R., OKOŃSKI, A. Układy paliwowe systemów wtryskowych silników ZI. Wydawnictwo Instalator Polski. Warszawa 2002.

[8] MADEJ, H. Diagnozowanie uszkodzeń mechanicznych w silnikach spalinowych maskowanych przez elektroniczne urządzenia sterujące. Wydawnictwo Naukowe Instytutu Technologii Eksploatacji. Radom 2009.

[9] MERKISZ, J. Ekologiczne aspekty stosowania silników spalinowych. Wydawnictwo Politechniki Poznańskiej. Poznań 1994.

[10] MERKISZ, J., MAZUREK, S. Pokładowe systemy diagnostyczne pojazdów samochodowych. Wydawnictwo Komunikacji i Łączności. Warszawa 2002.

Ewa Siemionek, DEng. - Faculty of Mechanical

Engineering, Lublin University of Technology.

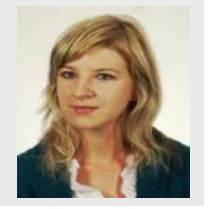

Paweł Żur, MEng. - Faculty of Mechanical Engineering, Lublin University of Technology.

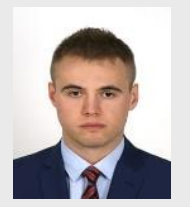

Dawid Tatarynow, MEng. - Faculty of Mechanical Engineering, Lublin University of Technology.

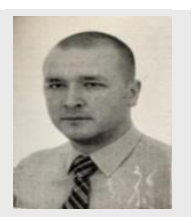

